\title{
IN MEMORIAM EKREM AKURGAL
}

Die Altertumswissenschaften trauern um Ekrem Akurgal, der mit 91 Jahren am 1. November 2002 verstorben ist. In seinem Lebenswerk verbinden sich Klassische Archäologie, Alt-Orientalistik sowie Ur- und Frühgeschichte mit Alter Geschichte. Durch die aktive Auseinandersetzung mit den wechselnden Einflüssen des Orients und des Okzidents auf die Kulturen der Hethiter, Urartäer, Phryger, Lyder, Karer und Lykier in Kleinasien wurde er zum Doyen der türkischen Altertumswissen-

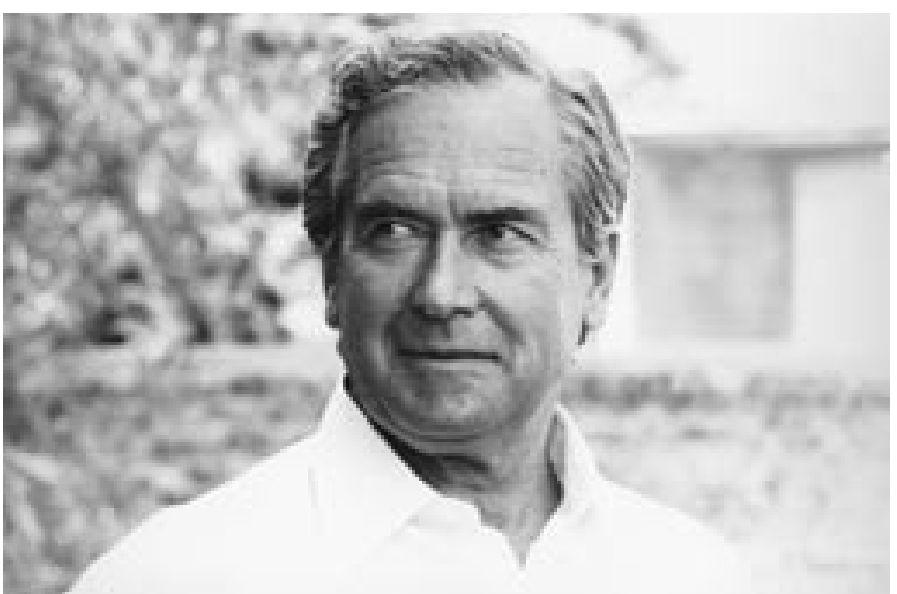

Ekrem Akurgal (†) schaften.

Am 30. März 1911 wurde Ekrem Akurgal auf dem Landgut seines Großvaters in Tulkarem bei Haifa im damaligen Palästina geboren. Einer aus dem nahe gelegenen Caesarea stammenden Münze aus dem 15. Jahrhundert n. Chr., die als Glücksbringer auf der linken Schulter seines Gewandes aufgenäht wurde, wird wegweisende Bedeutung zugeschrieben. 1913 erfolgt die Übersiedlung nach Istanbul, weshalb der Vater in der Geburtsurkunde vereinfachend »Istanbul« als Geburtsort eintragen läßt. Aufwachsen und seine Ferien verbringen wird der junge Ekrem aber auf dem Gut seines Vaters in Akyazı bei Adapazarı, im ehemals antiken Bithynien. Er liebte die Rückkehr der Herden am Abend, das Reiten auf einem Araber, den Tanz der Georgier und Abchasen in den umliegenden Dörfern und die Ölringkämpfe, mit denen er sich später in seiner Dissertation beschäftigte, die festliche Atmosphäre von Hochzeiten und Pferderennen. Sowohl auf dem Gut als auch in der Stadtwohnung seines Onkels in Istanbul gab es kleine Bibliotheken. Mit dem Vater, dem vielseitig interessierten Gutsbesitzer, wurden die Reformen Atatürks diskutiert, die Mutter bewunderte er für ihre Leseabende für die meist analphabetischen Frauen der Nachbarschaft. Von seinem geliebten Onkel, der 1918 aus dem österreichischen Bosnien-Herzegowina nach einer Beschwerde beim Kaiser durch den Sultan Mehmet VI. als Direktor einer Schule für arabische Literatur nach Istanbul geholt wurde und dort ein großes Haus führte, spricht er voller Hochachtung.

Als polyglotter Forscher und Lehrer, als bewunderter Erzähler und überzeugter Kosmopolit, der seit seinem Studium viel Zeit in den Großstädten der Türkei und Europas verbrachte, u. a. als Gastprofessor nach seiner Emeritierung in Wien, konnte er auf Grund seiner glücklichen Kindheit auf dem Lande seinem Ausgräberleben in Alt-Smyrna (1948-1951, 1965-2002), Sinope (1951-1953), Phokaia (1952), Daskyleion (1954-1955), Pitane (1960-1965) und Erythrai (1977-1983) auch immer angenehme Seiten abgewinnen.

Nach der Grundschule und der Mittelschule beendete er 1931 in Istanbul erfolgreich das Lyzeum, zuletzt als Internatsschüler mit starker Hinwendung zu einer französisch geprägten Bildung.

Wie Johann Jakob Bachofen und Roland Hampe widmete sich Ekrem Akurgal zunächst dem Jurastudium. Seine Neigungen aber galten der Archäologie. Durch Eigenstudium gewann er das Stipendium des Erziehungsministeriums der Türkischen Republik für Archäologie in Deutsch- 
land und begann nach einem Jahr auf dem Gymnasium Schulpforta zur Vervollständigung seiner deutschen Sprachkenntnisse das Studium der Klassischen Archäologie, Klassischen Philologie und Kunstgeschichte an der Humboldt-Universität in Berlin bei Gerhard Rodenwaldt. Im Rahmen des neuen türkischen Personennamengesetzes vom 21. Juni 1934, das nach europäischem Vorbild Familiennamen vorschrieb, wählte er im fernen Berlin nach damaliger türkischer Auffassung, daß die sumerischen und hethitischen Sprachen mit den Turksprachen verwandt seien, den Namen Akurgal, entweder in der Bedeutung von »Sohn des großen Landes«, um seine Heimatverbundenheit auszudrücken, oder aber nach dem historischen A.KUR.GAL, dem Sohn des Urnanše, der um 2500 v. Chr. König von Lagaš war.

1940 promoviert Ekrem Akurgal auf den Spuren seines Doktorvaters mit dem Thema »Griechische Reliefs des VI. Jahrhunderts aus Lykien«. Diese Liebe zur lykischen Kultur hat ihn sein Leben lang begleitet; großzügig unterstützte er in- und ausländische Forschungen und war verehrter Mittelpunkt sowohl des ersten 1977 von Paul Demargne und Henri Metzger einberufenen Internationalen Lykien-Symposions in Istanbul als auch des zweiten Kongresses 1990 in Wien.

Nach seiner Rückkehr in die Türkei erhält er 1941 in Ankara eine Assistentenstelle, habilitiert, beginnt 1948 mit der Ausgrabung in Bayrakl1/Smyrna und wird 1949 zum Professor ernannt. Von 1944-1953 wurde in Ankara nach den Plänen von Emin Onat und Orhan Arda das Mausoleum des 1938 verstorbenen Staatsgründers Atatürk erbaut. Ekrem Akurgal war Mitglied einer für die Ausstattung mit Skulpturen und Reliefs zuständigen Kommission: die Antikenrezeption ist unübersehbar.

Von 1957-1981 wirkte er als Ordinarius auf dem Lehrstuhl in Ankara und bildete zahlreiche Schüler und Schülerinnen aus, die ihrerseits wiederum die meisten Lehrstühle an den alten und neu eingerichteten Universitäten der Türkei eingenommen haben. Die Hethiter müssen zeitlebens eine große Herausforderung gewesen sein, wie seine Antworten beweisen: »Späthethitische Bildkunst« (1949), »Die Kunst der Hethiter« (1961), »Hatti ve Hitit Uygarlıkları« (1955).

In regelmäßigen Abständen legte er Arbeiten vor, welche die gesamte Türkei umfassen: »Die Kunst Anatoliens von Homer bis Alexander« (1961); »Das Anatolien der Frühen Königreiche«, in: »Die Türkei und ihre Kunstschätze« (1966); »Ancient Civilizations and Ruins of Turkey« (1969), »Griechische und römische Kunst in der Türkei« (1987). Dieses Bemühen des Hochschullehrers und zeitweiligen Dekans um öffentliches Interesse für sein Fach entsprang natürlich der Überzeugung, daß Geschichte und Archäologie bei der Identitätsstiftung der Türkischen Republik eine große Rolle spielen müßten. Ekrem Akurgal hat sich aber weder ideologisch noch methodisch vereinnahmen lassen. Städtebauliche Konzepte und baugeschichtliche Probleme haben ihn immer genauso fasziniert wie Probleme narrativer Kunst oder kunsthistorische Fragen der Generation in der Nachfolge von Wilhelm Pinder oder Antworten der Wiener Schule von Alois Riegl und Franz Wickhoff auf Strukturen oder kontinuierende Darstellungsweisen. Bahnbrechend und mutig war seine Grabung in Daskyleion, dem Satrapensitz am Manyas-See: der Zeit der 200jährigen Herrschaft der Achaimeniden in Kleinasien und der sog. graeco-persischen Kunst vor Alexander dem Großen und dem Hellenismus wurde endlich die gebührende Aufmerksamkeit geschenkt.

Die Erhellung des ionischen Griechentums in Kleinasien aber blieb das Hauptthema. So heißt sein Werk »Orient und Okzident« (1966) bezeichnenderweise im Untertitel »Die Geburt der griechischen Kunst«. Zahlreiche Aufsätze und der Band »Alt-Smyrna I. Wohnschichten und Athenatempel« (1983) bezeugen sein Bemühen um die Dokumentation der Schichtenabfolge und die Erforschung gesellschaftlicher Strukturen mit der Blüte von Kultur, Philosophie und Kunst im archaischen Ionien.

In Izmir verbrachte er seine letzten Jahre zusammen mit seiner zweiten Frau Meral Akurgal, geborene Manyas, Professorin an der 9. Eylül-Universität. Ein Herzenswunsch von seiner Seite war es, daß die wiederzueröffnende Dependance des Österreichischen Archäologischen Instituts nicht in Istanbul oder Ankara, sondern ebenfalls in Izmir stationiert werden sollte. Aus seiner Überzeugung, daß die Türkei gebend und nehmend ein wertvolles, fruchtbares Mitglied Europas ist, entstand auch sein Vorschlag, Kaya, das antike Karmylessos, bei Fethiye, dem antiken Telmessos, zu einer Stätte der Aussöhnung zwischen Griechen und Türken zu machen. 
Der Forscher, Freund und Förderer des inländischen und ausländischen Nachwuchses wurde als Ehrenmitglied des Deutschen und des Österreichischen Archäologischen Instituts ausgezeichnet, als Korrespondierendes Mitglied britischer, deutscher, französischer und italienischer Akademien geehrt. Er war von 1972-1997 Mitglied der Kleinasiatischen Kommission der Österreichischen Akademie der Wissenschaften und wurde zum Dr.phil.h.c. der Universitäten von Athen, Bordeaux, Eskişehir und Lecce ernannt.

Goethes Wort zum Tode von Johann Joachim Winckelmann möge uns Verpflichtung sein: »Von seinem Grabe her stärkt uns der Anhauch seiner Kraft und erregt in uns den lebhaftesten Drang, das, was er begonnen, mit Eifer und Liebe fort und immer fortzusetzen.«

Wien, im Mai 2003

em. Prof. Dr. Jürgen Borchhardt

Rennweg 89/1/5, A-1030 Wien

Abbildungsnachweis: Photo privat. 
